\title{
Melting and crystallization DSC profiles of milk fat depending on selected factors
}

\author{
Jolanta Tomaszewska-Gras
}

Received: 14 October 2012/ Accepted: 19 February 2013/Published online: 20 March 2013

(c) The Author(s) 2013. This article is published with open access at Springerlink.com

\begin{abstract}
The aim of this study was to test selected factors, such as sample preparation and measurement procedure, potentially influencing repeatability of DSC analysis of milk fat melting and crystallization. The study investigated the effect of such factors as scanning rate, type of sample pans, method of butter dehydration, and final temperature in the cooling experiment. Based on recorded results, it was observed that cooling rate has a considerable effect on temperature, enthalpy, and height of peaks in the process of milk fat crystallization, as well as peak height and enthalpy in the melting process. By contrast, in the melting process no significant differences were observed in all measured temperatures in the range of heating rate of $2-20{ }^{\circ} \mathrm{C} \mathrm{min}-1$ $(p>0.05)$. No statistically significant effect on thermodynamic parameters was found for sample pan type, the applied butter dehydration method and various final cooling temperatures $\left(-60,-50\right.$, and $\left.-40{ }^{\circ} \mathrm{C}\right)$ either in the melting or crystallization processes. Only temperature of the second peak $\left(T_{\mathrm{c}} 2\right)$ in the crystallization process constituted an exception in this respect, with significant differences ( $p \leq 0.05$ ) being recorded depending on the applied pan and dehydration method. With regard to the dehydration method, for the extraction and centrifugation methods the first peak forming during crystallization was characterized by high instability, manifested by various peak shape. Generally, it was found that the analysis of the melting and crystallization processes in milk fat, despite its complex composition, is characterized by high repeatability. Mean values of RSD calculated from all the experiments were very low, i.e., $1.8 \%$
\end{abstract}

J. Tomaszewska-Gras ( $\square)$

Department of Food Quality Management, Poznań University

of Life Sciences, ul. Wojska Polskiego 31,

60-637 Poznan, Poland

e-mail: gras@up.poznan.pl for the temperature in the melting process and $1.5 \%$ in crystallization, $0.9 \%$ for melting enthalpy, and $3.2 \%$ for crystallization enthalpy, whereas for peak heights in melting it was $2.9 \%$ and for crystallization it was $9.3 \%$, respectively.

Keywords Milk fat - Melting - Crystallization · Differential scanning calorimetry (DSC)

\section{Introduction}

Differential scanning calorimetry (DSC) promises to offer a sensitive, rapid, and reproducible fingerprint method for the identification of edible oils and fats [1]. In recent years, publications have been presented indicating the applicability of DSC in the evaluation of authenticity of edible fats [2-7]. In order to identify fat adulteration, a method has to exhibit high accuracy, understood as trueness and precision, linearity, and stability, i.e., resistance to various factors [8]. Recently, DSC has been proposed as an analytical technique for the analysis of food and pharmaceuticals $[9,10]$. Measurement precision is determined by several factors such as equipment, operator, measurement procedure, sample preparation, etc. For the determination of DSC suitability, it is crucial to identify factors affecting repeatability of measurements. These include, e.g., instrumental factors, which are common for all tested substances, i.e., pan type, sample mass, heating, and cooling rates. In case of heterogeneous organic substances with a complex composition, such as, e.g., food, also methodological factors and factors connected with variability of raw materials may be considered. Factors connected with methodology of analyses may also include, e.g., the manner of sample preparation, butter dehydration, or temperature conditions of analyses. Butter is a water-in-oil emulsion, thus in order 
to examine pure milk fat it needs to be dehydrated. Removal of water is required in case of DSC analyses due to interferences connected with phase transformations of water. In numerous publications concerning butter analyzed using DSC [11, 12], various procedures of its dehydration were used, employing both physical and chemical methods. For example, dehydration by evaporation [4], by centrifugation [2, 3, 13], centrifugation and evaporation [14], and extraction [15] were applied. However, there are no studies comparing the melting and crystallization processes for milk fat in case of different butter dehydration methods. The aim of this study was to test selected factors such as sample preparation and measurement procedures, potentially affecting measurement repeatability of melting, and crystallization of milk fat (butterfat) by DSC.

\section{Experimental}

Standard procedure

A Perkin Elmer differential scanning calorimeter DSC 7 (Perkin Elmer, Norwalk) equipped with an Intracooler II and running under Pyris software was used for examination of melting and crystallization properties of milk fat from butter. Nitrogen $(99.999 \%$ purity) was the purge gas. The DSC calorimeter was calibrated using indium (m.p. $156.6{ }^{\circ} \mathrm{C}, \Delta H_{\mathrm{f}}=28.45 \mathrm{~J} \mathrm{~g}^{-1}$ ) and $n$-dodecane (m.p. $-9.65{ }^{\circ} \mathrm{C}, \Delta H_{\mathrm{f}}=216.73 \mathrm{~J} \mathrm{~g}^{-1}$ ). Samples of ca. $10 \mathrm{mg}$ were weighed into aluminum pans of $20 \mu \mathrm{l}$ (Perkin Elmer, No. 0219-0062) and hermetically sealed. The reference was an empty, hermetically sealed aluminum pan. Prior to analysis the samples were heated at $50{ }^{\circ} \mathrm{C}$ for 5 min to melt all crystals and nuclei. In the standard procedure, crystallization curves were recorded from 50 to $-40{ }^{\circ} \mathrm{C}$ at a cooling rate of $5{ }^{\circ} \mathrm{C} \mathrm{min}^{-1}$. Then, following cooling, melting curves were recorded from -40 to $60{ }^{\circ} \mathrm{C}$ at $5{ }^{\circ} \mathrm{C} \min ^{-1}$. The calibration of the calorimeter was controlled with capric acid melting (m.p. $31.6{ }^{\circ} \mathrm{C}$ ). The temperature of the beginning of crystallization $\left(T_{\mathrm{c}}\right.$ on) and of each peak $\left(T_{\mathrm{c}} 1, T_{\mathrm{c}} 2\right)$, enthalpy of crystallization $\Delta H_{\mathrm{c}}$ $\left(\mathrm{J} \mathrm{g}^{-1}\right)$, and peak hight $\left(h_{\mathrm{c}} 1, h_{\mathrm{c}} 2\right)\left(\mathrm{W} \mathrm{g}^{-1}\right)$ were measured from cooling curves, as shown in Fig. 1. The following parameters were analyzed for the melting process (Fig. 1): $T_{\mathrm{m}} 1$ is the melting point for the first peak (melting of the low melting fraction, LMF), $T_{\mathrm{m}}$ on, $T_{\mathrm{m}} 2$ are the temperature of the onset and temperature of the second melting peak of the medium melting fraction (MMF), $T_{\mathrm{m}}$ end is the final melting temperature (clarification temperature), and enthalpy $\Delta H_{\mathrm{m}}\left(\mathrm{J} \mathrm{g}^{-1}\right)$ determined as the area, limited by the melting curve and base line. Moreover, height of peaks $h_{\mathrm{m}} 1$, $h_{\mathrm{m}} 2, h_{\mathrm{m}} 3\left(\mathrm{~W} \mathrm{~g}^{-1}\right)$ was calculated per $1 \mathrm{~g}$ sample. All measurements were performed in triplicate for each sample.

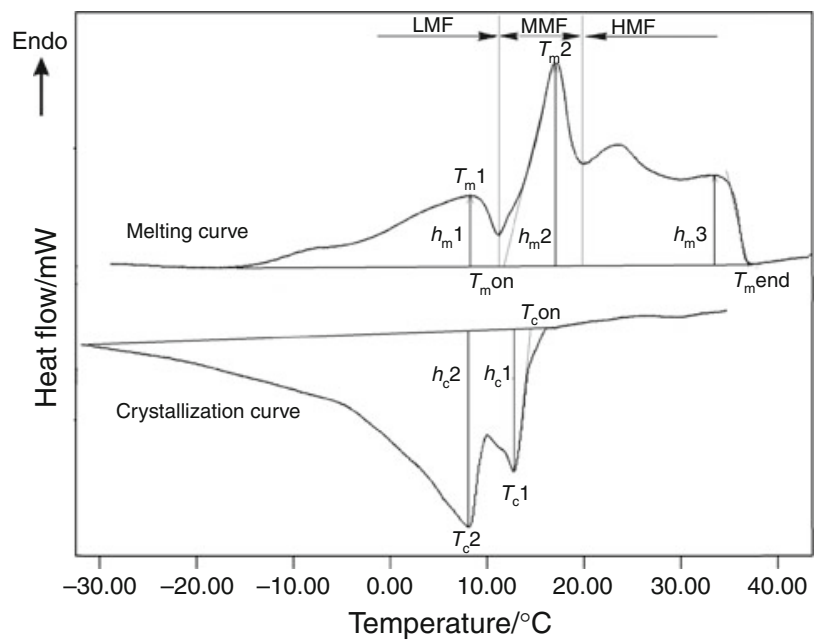

Fig. 1 Typical DSC curve of crystallization and melting of milk fat, scanning rate $5{ }^{\circ} \mathrm{C} \mathrm{min}^{-1}$. $L M F$ low melting fraction, $M M F$ medium melting fraction, $H M F$ high melting fraction

Influence of scanning rate

The samples were cooled and heated at five scanning rates, namely $1,2,5,10$, and $20^{\circ} \mathrm{C} \mathrm{min}^{-1}$. Each DSC scan was collected on a new sample to ensure that all of the samples started with the same thermal history. For each scanning rate, the calibration procedure was completed with the same scanning rate. The experiment was performed in two replications.

The effect of sample pan

Two types of pans were compared of $20 \mu \mathrm{l}$ (Perkin Elmer, No. 0219-0062) and of $50 \mu \mathrm{l}$ (Perkin Elmer, No. B0169321). Analyses of crystallization and melting were conducted according to the standard procedure. Samples of $\sim 10 \pm 0.5 \mathrm{mg}$ were weighed to two types of pans. The experiment was performed in two replications.

The effect of final cooling temperature on the melting profile

At this stage of analyses, different final temperatures were applied during cooling of milk fat, i.e., $-40,-50$, and $-60{ }^{\circ} \mathrm{C}$. The experiment was performed in two replications.

The effect of dehydration method of butter sample

This experiment comprised analyses of different dehydration methods applied on butter samples in order to obtain pure milk fat:

- Dehydration of butter samples in a water bath at a temperature of $100{ }^{\circ} \mathrm{C}$ by evaporation of water. 
- Dehydration of butter samples using a centrifuge (6,000 $\left.\mathrm{rpm}^{-1}, 10 \mathrm{~min}\right)$.

- Dehydration using extraction of fat with the use of solvents (hexane) according to the methodology [15].

The whole experiment was repeated twice.

Statistical analysis of results

Results were presented in the form of a mean, standard deviation, and relative standard deviation (RSD). The first stage in the statistical analysis consisted in the verification of variance homogeneity using the Hartley-CochornBartlett test. In case of variance homogeneity, one-way analysis of variance (ANOVA) was used and Tukey's test was applied to create statistically homogeneous groups. In turn, when variances were not homogeneous, nonparametric tests were used, i.e., ANOVA and the KruskalWallis rank test. Statistical analysis of recorded results was performed using Statistica 10.0 software (StatSoft. Inc., USA) at the significance level $p=0.05$.

\section{Results and discussion}

The effect of cooling rate on the crystallization profile and heating rate on the melting profile of milk fat

Figure 2 presents crystallization curves obtained using different cooling rates $\left(1,2,5,10\right.$, and $\left.20^{\circ} \mathrm{C} \min ^{-1}\right)$. On all crystallization curves, two exothermic peaks $\left(T_{\mathrm{c}} 1, T_{\mathrm{c}} 2\right)$ can be observed. The shape of the curve as well as heights of crystallization peaks of milk fat change depending on cooling rate (curves are presented in the same scale). Crystallization peaks become smaller with a decreasing cooling rate, which results in a reduction of sensitivity of the method. The upper graph in Fig. 2 presents in enlarged scale crystallization curves for the rates of 1 and $2{ }^{\circ} \mathrm{C} \mathrm{min}^{-1}$. Despite the fact that for low rates $\left(1-2{ }^{\circ} \mathrm{C} \mathrm{min}^{-1}\right)$ sensitivity decreases, the resolution of the peaks increases. Peaks $T_{\mathrm{c}} 1$ and $T_{\mathrm{c}} 2$ are sharp and well separated. In turn, the application of high cooling rates, e.g., $20{ }^{\circ} \mathrm{C} \mathrm{min}-1$, results in a deterioration of resolution and peaks $T_{\mathrm{c}} 1$ and $T_{\mathrm{c}} 2$ are not separated ( $T_{\mathrm{c}} 1$ peak is hardly visible). For all investigated cooling rates, different transition temperatures were recorded. The temperature, at which milk fat begins to crystallize $\left(T_{\mathrm{c}} \mathrm{on}\right)$, decreases with an increase in cooling rate from $21.35{ }^{\circ} \mathrm{C}$ for the rate of $1{ }^{\circ} \mathrm{C} \mathrm{min}{ }^{-1}$ to $11.1^{\circ} \mathrm{C}$ for the rate of $20{ }^{\circ} \mathrm{C} \mathrm{min}{ }^{-1}$. Similar dependencies in milk fat were also observed by others authors $[15,16]$. It is a different situation than in case of pure substances. According to the physics, the onset values for pure substances should be practically identical even



Fig. 2 Crystallization DSC curves of milk fat with various cooling rate $\left(1,2,5,10\right.$, and $\left.20{ }^{\circ} \mathrm{C} \min ^{-1}\right)$

with different scanning rates. For the tested fat, which is a mixture of triacylglycerols, various cooling rates cause different courses of crystallization, which is manifested in different shapes of peaks, their sizes, degree of separation, as well as different temperatures resulting from the occurrence of triacylglycerol polymorphisms.

Similarly as in case of temperature $T_{\mathrm{c}}$ on, values of peak temperatures $\left(T_{\mathrm{c}} 1, T_{\mathrm{c}} 2\right)$ and enthalpy $\Delta H_{\mathrm{c}}$ of crystallization also decrease with an increase in cooling rate. For the rate of $1{ }^{\circ} \mathrm{C} \mathrm{min}{ }^{-1}$ two peaks $T_{\mathrm{c}} 1$ and $T_{\mathrm{c}} 2$ appear at 20.7 and $15.8{ }^{\circ} \mathrm{C}$, while for the rate of $20^{\circ} \mathrm{C} \mathrm{min}^{-1}$ these peaks are found at 4.1 and $-1.2{ }^{\circ} \mathrm{C}$. Differences between mean values of temperatures and enthalpy for all rates were statistically significant $(p \leq 0.05)$. The dependences between cooling rate and temperature as well as enthalpy are presented in Fig. 3. The highest values of goodness of fit $R^{2}$ were obtained for the logarithmic dependence. It was 


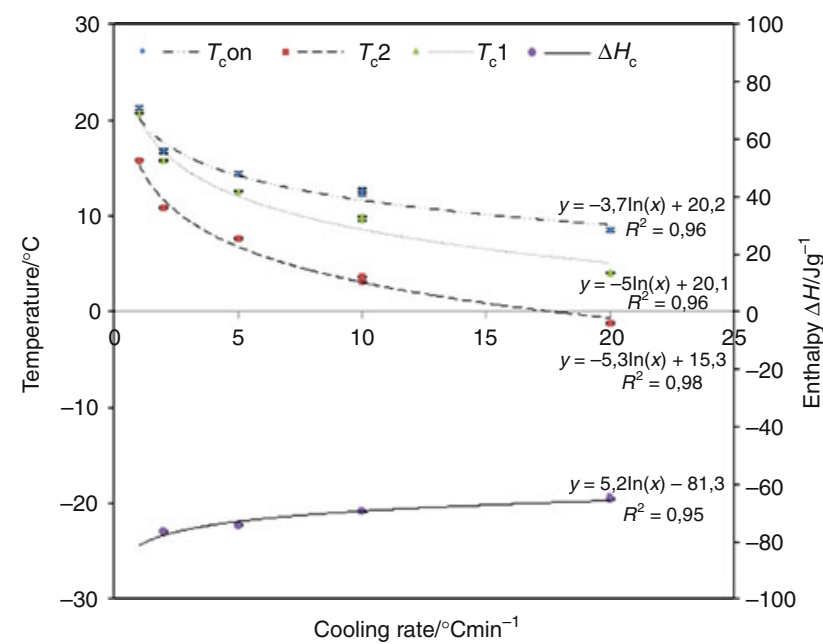

Fig. 3 Influence of cooling rate on the temperature and enthalpy of milk fat crystallization $\left(T_{\mathrm{c}}\right.$ on, $\left.T_{\mathrm{c}} 1, T_{\mathrm{c}} 2, \Delta H_{\mathrm{c}}\right)$

observed that for the rate of $1^{\circ} \mathrm{C} \mathrm{min}{ }^{-1}$ values of crystallization points are shifted more markedly than in case of other rates, which may results from a different mechanisms of crystallization at very low rates and the formation of other polymorphic forms with higher crystallization points. This was confirmed by XRD analyses conducted by ten Grotenhuis et al. [16], who stated for cooling rate $\geq 2.5^{\circ} \mathrm{C} \mathrm{min}{ }^{-1}$ the formation of $\alpha$ forms together with the $\gamma$ form, while for the rate of $\leq 1{ }^{\circ} \mathrm{C} \min ^{-1}$ found mainly the formation of a more stable form $\beta^{\prime}$, with a higher crystallization point. The recorded values of temperatures and enthalpy at different cooling rates are very similar to those presented by Lopez et al. [15] and ten Grotenhuis et al. [16]. A reduction of crystallization point for triacylglyceroles with an increase in cooling rate was also found in pure triacylglycerols [17] and different vegetable oils [18-20]. As it was stated by Metin and Hartel [21] fat crystallization is greatly influenced by the cooling rate, which affects crystalline microstructure and nucleation rate, governing crystal size. Rapid cooling to a low temperature promotes a higher nucleation rate, which leads to the formation of numerous small crystals [22]. When a fat is cooled very slowly, large crystals form. Marangoni and Hartel [23] used confocal microscopy to show that slowly cooled milk fat formed spherulitic crystals, whereas rapidly cooled milk fat formed random crystalline strands.

This study was also conducted on the process of melting at different scanning rates. Figure 4 presents melting curves obtained at different heating rates $(1,2,5,10$, and $20{ }^{\circ} \mathrm{C} \min ^{-1}$ ), following cooling of samples with the same rates to final temperature of $-40{ }^{\circ} \mathrm{C}$. As it was presented in Fig. 4, varied cooling and heating rates (from 1 to $20{ }^{\circ} \mathrm{C} \min ^{-1}$ ) influence changes in the melting process of milk fat. Similarly as in the process of crystallization, the shape of curves, the size of peaks, and their number

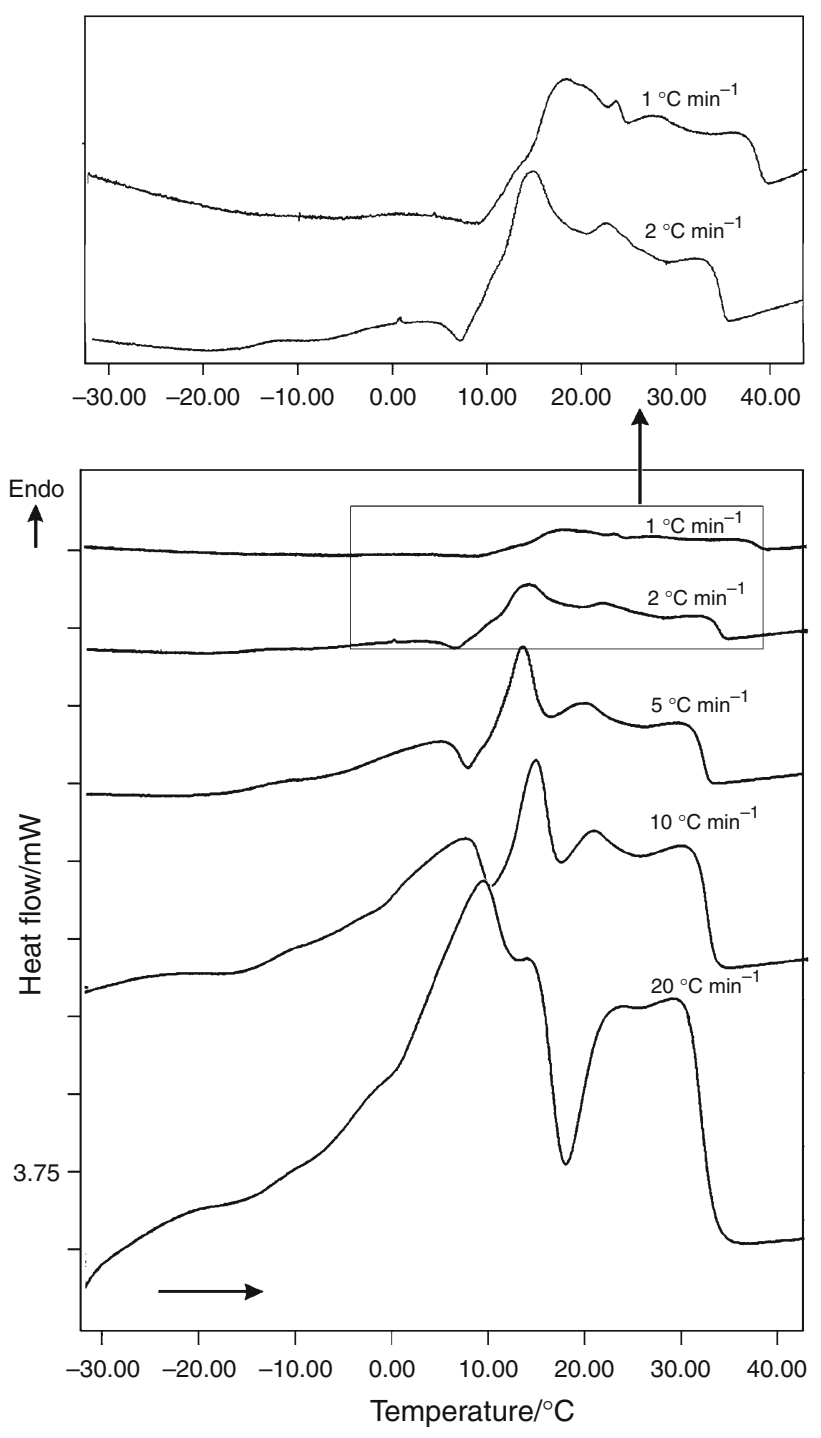

Fig. 4 Melting DSC curves of milk fat with various heating rates (1, $2,5,10$, and $20{ }^{\circ} \mathrm{C} \mathrm{min}^{-1}$ )

change, while only for rates of 5 and $10{ }^{\circ} \mathrm{C} \mathrm{min}-1$ a certain similarity of shape can be observed. Analogously as in case of crystallization, a reduction of heating rate causes a decrease in peak heights (Fig. 5). Values of measured temperature and enthalpy parameters are presented in Table 1. In contrast to the crystallization process, in the melting process no statistically significant differences were found between values of temperatures $\left(T_{\mathrm{m}} 1, T_{\mathrm{m}} \mathrm{on}, T_{\mathrm{m}} 2\right.$, $T_{\mathrm{m}}$ end) in the range of heating rates from 2 to $20{ }^{\circ} \mathrm{C} \mathrm{min}^{-1}$. A lack of significant differences between values of final melting temperature $\left(T_{\mathrm{m}}\right.$ end) were also found in other studies $[15,16,24]$. Values of enthalpy did not differ for heating rates from 2 to $10{ }^{\circ} \mathrm{C} \mathrm{min}{ }^{-1}$, while significantly different values were recorded for 1 and $20{ }^{\circ} \mathrm{C} \mathrm{min}-1$. In case of the rate of $1{ }^{\circ} \mathrm{C} \mathrm{min}^{-1}$ significantly higher temperatures $\left(T_{\mathrm{m}} 1, T_{\mathrm{m}} \mathrm{on}, T_{\mathrm{m}} 2, T_{\mathrm{m}}\right.$ end $)$ were 


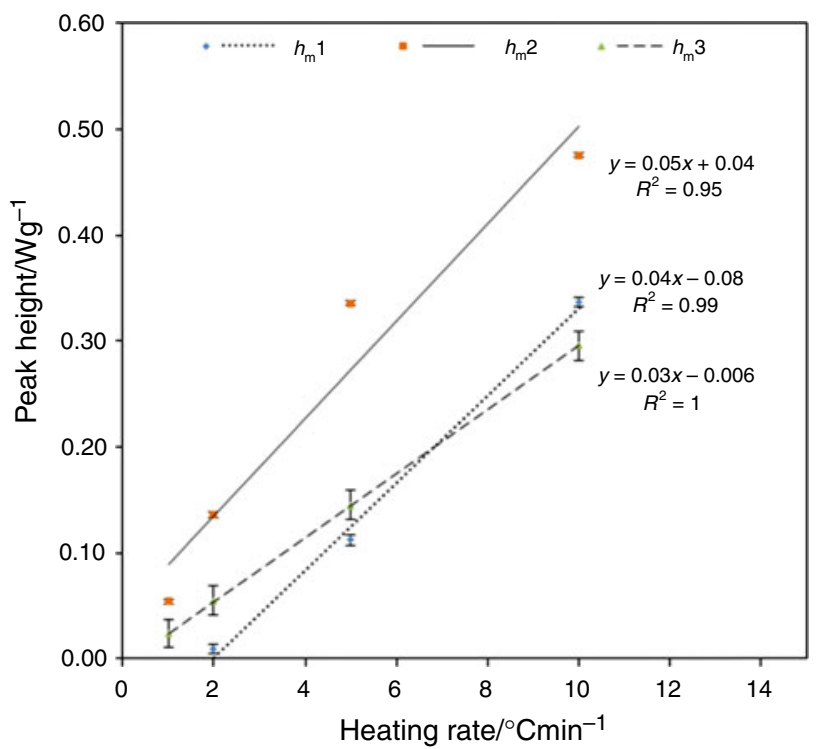

Fig. 5 Relationship between heating rate $(1,2,5,10$, and $\left.20{ }^{\circ} \mathrm{C} \min ^{-1}\right)$ and peak height $\left(h_{\mathrm{m}} 1, h_{\mathrm{m}} 2, h_{\mathrm{m}} 3\right)$ of melting process of milk fat

also found, which may confirm the formation of more stable crystalline forms. Ten Grotenhuis [16] using XRD observed that at a rate of $1{ }^{\circ} \mathrm{C} \mathrm{min}{ }^{-1}$ during crystallization only the stable $\beta^{\prime}$ form is formed. This phenomenon may be confirmed by the disappearance of the first peak T1 at a rate of $1{ }^{\circ} \mathrm{C} \mathrm{min}^{-1}$. As it was shown in Fig. 4, with a reduction of heating rate the LMF (the first peak) decreases and it is increasingly less visible. In the upper graph of Fig. 4 (curves in enlarged scale, for the rates of 1 and $2{ }^{\circ} \mathrm{C} \mathrm{min}^{-1}$ ) can be seen, that for $1{ }^{\circ} \mathrm{C} \min ^{-1}$ the peak of the LMF is practically invisible.

\section{The effect of applied pan type}

The aim of this experiment was to investigate whether the application of different aluminum pans (of different shapes and volumes), in which samples of milk fat are placed and analyzed, may have a significant effect on the obtained crystallization and melting curves. For this purpose, two

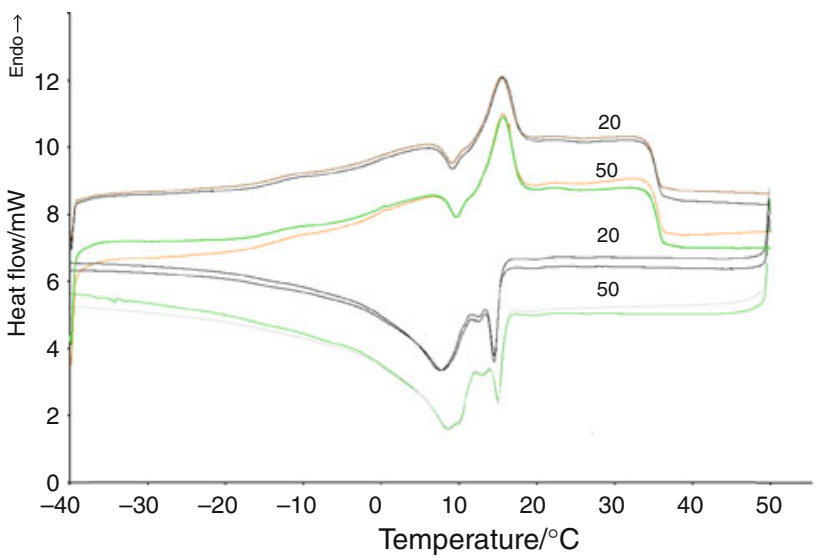

Fig. 6 Comparison of curves recorded for two types of sample pans $(20$ and $50 \mu \mathrm{l})$ used for DSC melting and crystallization analysis of milk fat at scanning rate $5{ }^{\circ} \mathrm{C} \mathrm{min}-1$

types of pans were examined, i.e., of 20 and $50 \mu \mathrm{l}$. Analyses of crystallization and melting processes were conducted according to the standard procedure. Obtained curves are presented in Fig. 6, on which can be observed very high similarity of the plotted crystallization and melting curves. Measured temperatures and peak heights are given in Fig. 7. It needs to be stressed here that in case of $50 \mu \mathrm{l}$ pans values of temperatures both for crystallization and melting are higher. However, the conducted statistical tests showed that only in case of temperature $T_{\mathrm{c}} 2$ in the crystallization process the differences were statistically significant $(p \leq 0.05)$. Moreover, it was shown that measurements were characterized by high repeatability, as manifested by RSD values presented in Table 2 . As it is shown they ranged from 1.4 and $9.5 \%$. For measured temperatures of crystallization and melting processes RSD was on average $3 \%$, for the measurements of enthalpy it was $3.9 \%$, while for the measurement of peak heights it was $6.2 \%$.

The effect of final cooling temperature of milk fat

The aim of this stage was to compare curves for melting of milk fat samples, cooled to different final temperatures,

Table 1 Temperatures and enthalpies of milk fat melting process depending on heating rate

\begin{tabular}{|c|c|c|c|c|c|}
\hline \multirow[t]{2}{*}{ Heating rate $/{ }^{\circ} \mathrm{C} \min ^{-1}$} & \multicolumn{4}{|c|}{ Temperature $/{ }^{\circ} \mathrm{C}$} & \multirow{2}{*}{$\begin{array}{l}\text { Enthalpy } / \mathrm{J} \mathrm{g}^{-1} \\
\Delta H_{\mathrm{m}}\end{array}$} \\
\hline & $T_{\mathrm{m}} 1$ & $T_{\mathrm{m}}$ on & $T_{\mathrm{m}} 2$ & $T_{\mathrm{m}}$ end & \\
\hline 1 & - & $13.16^{\mathrm{b}} \pm 0.22$ & $18.1^{\mathrm{c}} \pm 0.19$ & $41.02^{\mathrm{b}} \pm 0.12$ & $68.3^{\mathrm{a}} \pm 0.31$ \\
\hline 2 & - & $9.51^{\mathrm{a}} \pm 0.13$ & $14.17^{\mathrm{a}} \pm 0.16$ & $36.01^{\mathrm{a}} \pm 0.17$ & $76.33^{b} \pm 0.27$ \\
\hline 5 & $5.75^{\mathrm{a}} \pm 0.17$ & $9.44^{\mathrm{a}} \pm 0.12$ & $14.95^{\mathrm{b}} \pm 0.14$ & $36.25^{\mathrm{a}} \pm 0.16$ & $77.44^{b} \pm 0.35$ \\
\hline 10 & $7.30^{b} \pm 0.12$ & $9.54^{\mathrm{a}} \pm 0.39$ & $15.08^{\mathrm{b}} \pm 0.18$ & $35.62^{\mathrm{a}} \pm 0.17$ & $74.62^{\mathrm{a}} \pm 0.26$ \\
\hline 20 & - & - & - & $36.33^{\mathrm{a}} \pm 0.21$ & $68.32^{\mathrm{a}} \pm 0.30$ \\
\hline
\end{tabular}

$\pm S D$ group averages \pm standard deviations, $a, b, c$ group averages with different superscripts differ significantly within columns $(p \leq 0.05)$ 
Fig. 7 Influence of sample pan type $(20$ and $50 \mu \mathrm{L})$ on peak height (a) and temperature

(b) of crystallization and melting process of milk fat
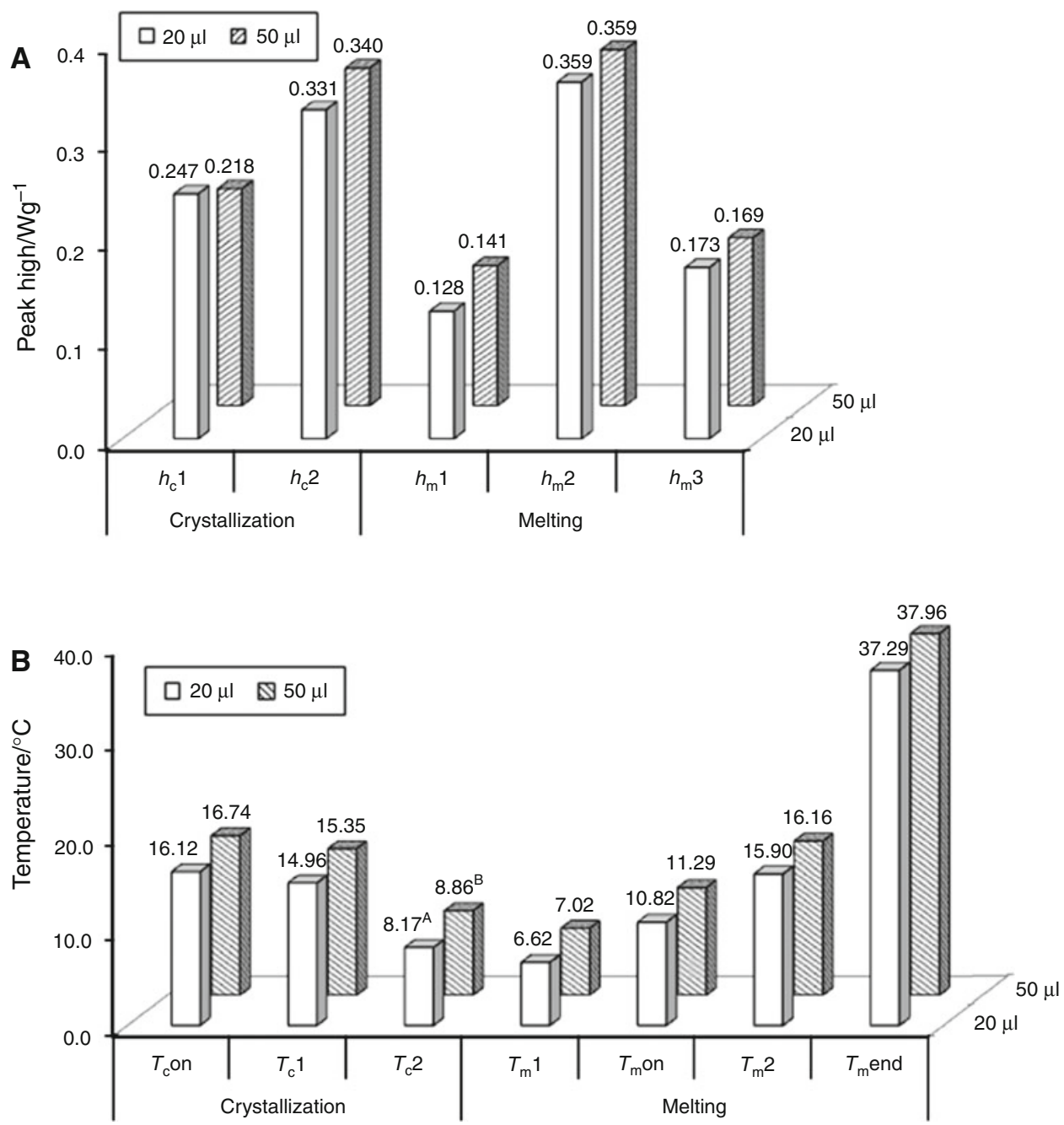

Table 2 Relative standard deviation for all measurements of temperature, enthalpy, and peak high of melting and crystallization of milk fat in all experiments

\begin{tabular}{|c|c|c|c|c|c|c|c|c|c|c|c|c|c|c|}
\hline & \multicolumn{14}{|c|}{ Relative standard deviation RSD/\% } \\
\hline & \multicolumn{8}{|c|}{ Melting } & \multicolumn{6}{|c|}{ Crystallization } \\
\hline & $T_{\mathrm{m}} 1$ & $T_{\mathrm{m}}$ on & $T_{\mathrm{m}} 2$ & $T_{\mathrm{m}} \mathrm{end}$ & $\Delta H_{\mathrm{m}}$ & $h_{\mathrm{m}} 1$ & $h_{\mathrm{m}} 2$ & $h_{\mathrm{m}} 3$ & $T_{\mathrm{c}}$ on & $T_{\mathrm{c}} 1$ & $T_{\mathrm{c}} 2$ & $\Delta H_{\mathrm{c}}$ & $h_{\mathrm{c}} 1$ & $h_{\mathrm{c}} 2$ \\
\hline \multicolumn{15}{|c|}{ Sample pan type/ $\mu 1$} \\
\hline 20 & 5.0 & 2.9 & 1.9 & 1.7 & 1.1 & 7.3 & 3.3 & 4.7 & 3.4 & 2.5 & 5.7 & 5.9 & 3.4 & 5.0 \\
\hline 50 & 1.4 & 4.5 & 1.8 & 2.2 & 2.1 & 9.5 & 4.1 & 6.1 & 4.0 & 2.0 & 3.0 & 6.7 & 9.1 & 9.0 \\
\hline \multicolumn{15}{|c|}{ Final cooling temperature $/{ }^{\circ} \mathrm{C}$} \\
\hline-40 & 1.7 & 3.5 & 1.1 & 0.4 & 0.6 & 1.3 & 0.7 & 1.9 & & & & & & \\
\hline-50 & 1.5 & 0.4 & 1.8 & 0.7 & 0.7 & 5.8 & 0.6 & 1.9 & & & & & & \\
\hline-60 & 1.9 & 0.4 & 1.8 & 0.4 & 0.5 & 2.7 & 0.7 & 1.5 & & & & & & \\
\hline \multicolumn{15}{|c|}{ Dehydration method } \\
\hline $\mathrm{E}$ & 1.5 & 0.4 & 1.8 & 0.7 & 0.7 & 5.8 & 0.6 & 1.9 & 2.3 & 2.7 & 0.8 & 1.6 & 4.7 & 5.3 \\
\hline $\mathrm{C}$ & 2.5 & 4.6 & 1.0 & 0.7 & 0.6 & 2.6 & 1.6 & 1.1 & 2.8 & 0.0 & 1.7 & 0.7 & 23.4 & 2.7 \\
\hline EX & 3.1 & 3.4 & 1.4 & 0.5 & 0.7 & 1.5 & 2.9 & 0.5 & 3.0 & 1.2 & 2.2 & 1.2 & 29.1 & 1.1 \\
\hline Mean & 2.3 & 2.5 & 1.6 & 0.9 & 0.9 & 4.6 & 1.8 & 2.5 & 3.1 & 1.7 & 2.7 & 3.2 & 13.9 & 4.6 \\
\hline
\end{tabular}

$E$ evaporation, $C$ centrifugation, $E X$ extraction 


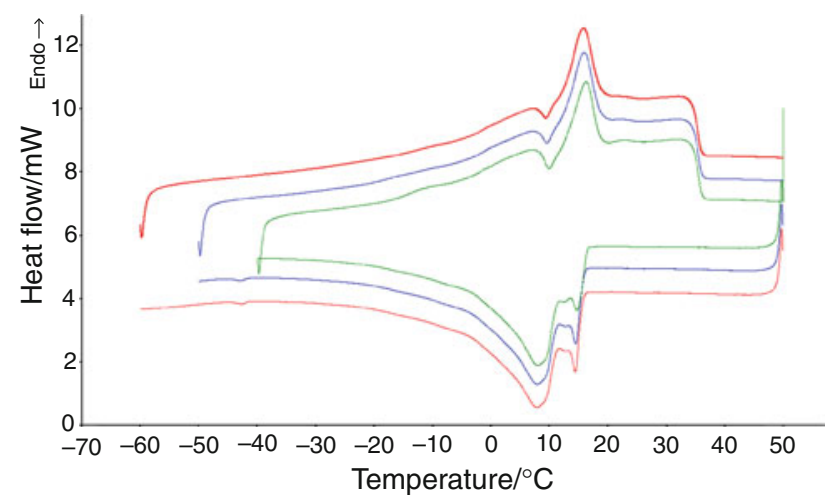

Fig. 8 DSC melting and crystallization curves of milk fat cooled to various final temperatures $\left(-40,-50\right.$, and $\left.-60{ }^{\circ} \mathrm{C}\right)$ at scanning rate $5{ }^{\circ} \mathrm{C} \min ^{-1}$ i.e., to $-40,-50$, and $-60{ }^{\circ} \mathrm{C}$. This analysis was to provide an answer to the question whether sample cooling to different final temperatures has a significant effect on the melting profile. Milk fat crystallizes and melts within a broad range of temperatures and crystallization ends with a very mild transition of the curve to the base line (Fig. 1), thus it was crucial to determine to what final temperatures we may cool the sample with no effect on the melting process. It can be observed in Fig. 8 that the plotted curves both for crystallization and melting show considerable similarity. Values of temperatures and enthalpy as well as peak heights recorded in the course of melting of milk fat are presented in the form of a graph (Fig. 9). Obtained results were analyzed statistically and no significant
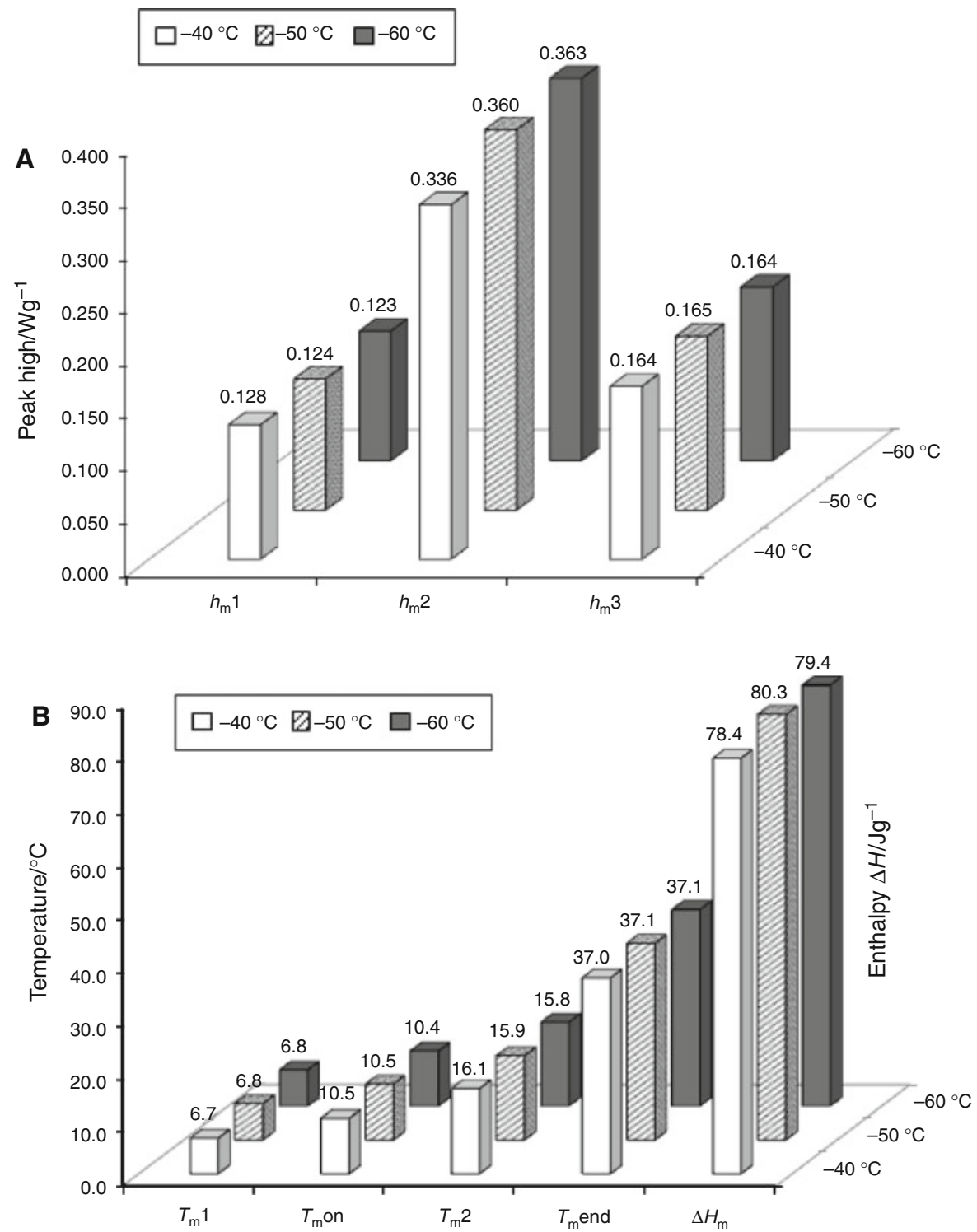

Fig. 9 Influence of cooling final temperature $\left(-40,-50\right.$, and $\left.-60^{\circ} \mathrm{C}\right)$ on peak height (a) and temperature, enthalpy (b) of melting process of milk fat 
differences were observed between parameters of temperatures, enthalpy, and peak heights recorded as a result of melting of milk fat samples cooled to different final temperatures. It may also be stated that measurements which are sums from two separate experiments were characterized by high repeatability (Table 2). For the measurement of temperature RSD was $1.3 \%$, for enthalpy $0.6 \%$ and for peak heights it was $1.9 \%$. Based on the obtained results in the standard procedure, the final sample cooling temperature of $-40{ }^{\circ} \mathrm{C}$ was applied.

The effect of butter dehydration method

In the literature containing results of DSC analyses conducted on milk fat collected from butter can be found different methods of its dehydration, i.e., evaporation,

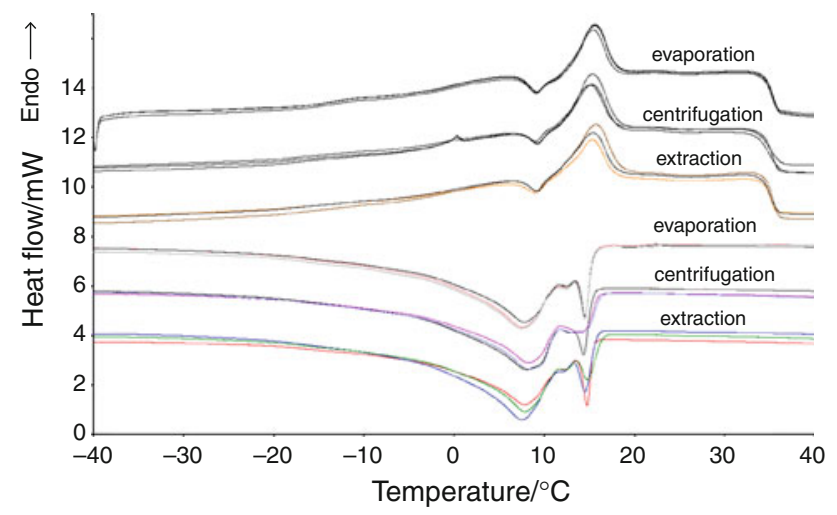

Fig. 10 DSC melting and crystallization curves of milk fat obtained from butter by various dehydration methods: evaporation, extraction, and centrifugation (scanning rate $5^{\circ} \mathrm{C} \mathrm{min}^{-1}$ ) centrifugation, or fat extraction using solvents (mainly hexane). The aim of this stage was to verify whether the applied dehydration method influences the profiles of crystallization and melting of anhydrous milk fat. Plotted curves are presented in Fig. 10, while the recorded results are given in Table 3. It may generally be stated that most analyzed parameters of temperature and enthalpy in the crystallization and melting processes the method of dehydration did not have a significant effect $(p>0.05)$. An exception in this respect was for the temperature of the second peak $T_{\mathrm{c}} 2$ in the crystallization process, for which significantly different values were obtained for the extraction method in relation to values recorded for the centrifugation and evaporation methods $(p \leq 0.05)$. Moreover, in the crystallization process it was observed that the heights of the first peak $h_{\mathrm{c}} 1$ differ considerably, although statistical tests did not show these differences to be significant. Particularly, for the extraction and centrifugation methods the forming first peak $h_{\mathrm{c}} 1$ during crystallization was characterized by high instability, as shown by the scatter of results. Coefficients of variation RSD of peak height $h_{\mathrm{c}} 1$ (Table 2) were $4.7 \%$ for evaporation, $23 \%$ for centrifugation, and $29 \%$ for extraction. These results may indicate that the application of a solvent in extraction or physical centrifugal force may influence fat crystallization. In case of centrifugation and extraction, it was difficult to obtain high repeatability of measured heights $h_{\mathrm{c}} 1$. When comparing obtained curves of crystallization for the three dehydration methods it may be observed that in case of evaporation all $h_{\mathrm{c}} 1$ peaks were sharp, while in case of centrifugation and extraction peaks were either sharp or flat. Similar flat peaks were obtained in a study by Lopez et al. [15], in which extraction was

Table 3 Thermodynamic parameters for melting and crystallization of milk fat depending on butter dehydration method

\begin{tabular}{|c|c|c|c|c|c|c|}
\hline \multicolumn{7}{|l|}{ Crystallization } \\
\hline & \multicolumn{3}{|c|}{ Temperature $/{ }^{\circ} \mathrm{C}$} & \multirow{2}{*}{$\begin{array}{l}\text { Enthalpy/J g }{ }^{-1} \\
\Delta H_{\mathrm{c}}\end{array}$} & \multicolumn{2}{|c|}{ Peak height/W $\mathrm{g}^{-1}$} \\
\hline & $T_{\mathrm{c}}$ on & $T_{\mathrm{c}} 1$ & $T_{\mathrm{c}} 2$ & & $h_{\mathrm{c}} 1$ & $h_{\mathrm{c}} 2$ \\
\hline Evaporation & $16.50 \pm 0.37$ & $15.17 \pm 0.41$ & $8.45^{\mathrm{b}} \pm 0.07$ & $-61.53 \pm 0.97$ & $-0.210 \pm 0,01$ & $-0.330 \pm 0.02$ \\
\hline Centrifugation & $16.30 \pm 0.45$ & $14.48 \pm 0.01$ & $8.37^{\mathrm{b}} \pm 0.14$ & $-59.99 \pm 0.43$ & $-0.198 \pm 0.05$ & $-0.312 \pm 0.01$ \\
\hline Extraction & $16.04 \pm 0.48$ & $14.77 \pm 0.18$ & $7.83^{\mathrm{a}} \pm 0.17$ & $-60.44 \pm 0.72$ & $-0.246 \pm 0.07$ & $-0.323 \pm 0.03$ \\
\hline
\end{tabular}

Melting

\begin{tabular}{|c|c|c|c|c|c|c|c|c|}
\hline & \multicolumn{4}{|c|}{ Temperature $/{ }^{\circ} \mathrm{C}$} & \multirow{2}{*}{$\begin{array}{l}\text { Enthalpy } / \mathrm{J} \mathrm{g}^{-1} \\
\Delta H_{\mathrm{m}}\end{array}$} & \multicolumn{3}{|c|}{ Peak height/W $\mathrm{g}^{-1}$} \\
\hline & $T_{\mathrm{m}} 1$ & $T_{\mathrm{m}} \mathrm{on}$ & $T_{\mathrm{m}} 2$ & $T_{\mathrm{m}}$ end & & $h_{\mathrm{m}} 1$ & $h_{\mathrm{m}} 2$ & $h_{\mathrm{m}} 3$ \\
\hline Evaporation & $6.84 \pm 0.10$ & $10.53 \pm 0.04$ & $15.88 \pm 0.29$ & $37.09 \pm 0.24$ & $80.30 \pm 0.55$ & $0.124 \pm 0.01$ & $0.360 \pm 0.00$ & $0.161 \pm 0.01$ \\
\hline Centrifugation & $6.60 \pm 0.17$ & $10.17 \pm 0.47$ & $15.42 \pm 0.16$ & $37.37 \pm 0.24$ & $79.92 \pm 0.49$ & $0.118 \pm 0.00$ & $0.352 \pm 0.01$ & $0.158 \pm 0.01$ \\
\hline Extraction & $6.48 \pm 0.20$ & $9.57 \pm 0.32$ & $15.65 \pm 0.22$ & $37.00 \pm 0.18$ & $79.59 \pm 0.59$ & $0.121 \pm 0.00$ & $0.343 \pm 0.01$ & $0.169 \pm 0.03$ \\
\hline
\end{tabular}

$\pm S D$ group averages \pm standard deviations, $a, b$ group averages with different superscripts differ significantly within columns $(p \leq 0.05)$ 
applied, while in case of evaporation [4] and centrifugation [2] a sharp first crystallization peak was reported.

In turn, in the melting process no significant differences were found between mean values of temperatures, enthalpy, or peak heights for the three methods applied to obtain pure milk fat $(p>0.05)$.

\section{Conclusions}

The shape of the DSC cooling and heating curves of milk fat depends on the scanning rate. Crystallization and melting peaks become larger with an increasing scanning rate. The initial $\left(T_{\mathrm{c}}\right.$ on) and peak temperatures $\left(T_{\mathrm{c}} 1, T_{\mathrm{c}} 2\right)$ as well as enthalpy in the crystallization process decreased with an increasing cooling rate. By contrast, in the melting process no significant differences were observed in temperatures in the range of heating rate $2-20{ }^{\circ} \mathrm{C} \mathrm{min}-1$ $(p>0.05)$. The use of pans of different volume did not have a significant effect on melting and crystallization of milk fat. Significant differences were recorded only for temperature $T_{\mathrm{c}} 2$ during crystallization $(p \leq 0.05)$. It was also stated that the final temperature, to which the milk fat sample is cooled $\left(-40,-50\right.$, and $\left.-60^{\circ} \mathrm{C}\right)$ has no significant effect on the melting profile. No significant differences were recorded for temperature, enthalpy, or peak heights in the melting process. In case of investigations on the effect of different methods of butter dehydration (evaporation, centrifugation of water, and fat extraction), it was found that for extraction significant differences occur in values of temperature $T_{\mathrm{c}} 2$ in the process of crystallization. Moreover, in case of centrifugation and extraction a considerable scatter of results was recorded for the determined heights of the first peak $h_{\mathrm{c}} 1$ in the process of crystallization. This may indicate the effect of these processes on the course of crystallization.

Regardless of the above observations, mean values of RSD calculated from all the experiments were very low, i.e., $1.8 \%$ for the temperature in the melting process and $1.5 \%$ in crystallization, $0.9 \%$ for melting enthalpy, and $3.2 \%$ for crystallization enthalpy, whereas for peak heights in melting it was $2.9 \%$ and for crystallization it was $9.3 \%$, respectively. The higher results of RSD for peak heights were caused mainly by the last experiment with different methods of butter dehydration.

Acknowledgments This research was supported by the National Science Centre, by Grant No. NN 312260538.

Open Access This article is distributed under the terms of the Creative Commons Attribution License which permits any use, distribution, and reproduction in any medium, provided the original author(s) and the source are credited.

\section{References}

1. Tan CP, Che Man YB. Comparative differential scanning calorimetric analysis of vegetable oils. I. Effects of heating rate variation. Phytochem Anal. 2002;13:129-41. doi:10.1002/ pca.633.

2. Coni E, Di Pasquale M, Coppolelli P, Bocca A. Detection of animal fats in butter by differential scanning calorimetry: a pilotstudy. J Am Oil Chem Soc. 1994;71:807-10. doi:10.1007/ BF02540453.

3. Tunick MH, Smith PW, Holsinger VH. Detection of recombined butter by DSC. J Therm Anal. 1997;49:795-9.

4. Aktas N, Kaya M. Detection of beef body fat and margarine in butterfat by differential scanning calorimetry. J Therm Anal Calorim. 2001;66:795-801. doi:10.1023/A:1013196106365.

5. Marikkar JMN, Ghazalia HM, Che Man YB, Laia OM. The use of cooling and heating thermograms for monitoring of tallow, lard and chicken fat adulterations in canola oil. Food Res Int. 2002;35:1007-14.

6. Chiavaro E, Vittadini E, Rodriguez-Estrada MT, Cerretani L, Bendini A. Differential scanning calorimeter application to the detection of refined hazelnut oil in extra virgin olive oil. Food Chem. 2000;110:248-56. doi:10.1016/j.foodchem.2008.01. 044.

7. Angiuli M, Bussolino GC, Ferrari C, Matteoli E, Righetti MC, Salvetti G, Tombari E. Calorimetry for fast authentication of edible oils. Int J Thermophys. 2009;30:1014-24. doi:10.1007/ s10765-009-0592-4.

8. ISO 5725-1. Accuracy (trueness and precision) of measurement methods and results. Part 1. General principles and definitions. 1994.

9. Tomaszewska-Gras J. Detection of butter adulteration with water using differential scanning calorimetry. J Therm Anal Calorim. 2012;108:433-8. doi:10.1007/s10973-011-1913-y.

10. Kaza L, Sobhi HF, Fruscella JA, Kaul C, Thakur S, Perera NI, Alexander K. Thermal analysis of water and magnesium hydroxide content in commercial pharmaceutical suspensions milk of magnesia. J Therm Anal Calorim. 2012;109:1365-71. doi:10.1007/s10973-012-2429-9.

11. Schaffer B, Szakaly S, Lorinczy D, Belagyi J. Structure of butter III. Effect of modification of cream ripening and fatty acid composition on the melting properties of butter fat. Milchwissenschaft. 1999;54:82-5.

12. Schaffer B, Szakaly S, Lorinczy D, Schaffer B. Melting properties of butter fat and the consistency of butter. Effect of modification of cream ripening and fatty acid composition. J Therm Anal Calorim. 2001;64:659-69.

13. Ortiz-Gonzalez G, Jimenez-Flores R, Bremmer DR, Clark JH, DePeters EJ, Schmidt SJ, Drackley JK. Functional properties of butter oil made from bovine milk with experimentally altered fat composition. J Dairy Sci. 2007;90:5018-31. doi:10.3168/jds. 2007013.

14. Lorinczy D, Regdon G, Keller B, Szakaly S, Schaffer B. Development of a DSC method for determination of certain technological parameters of margarine and mixed-fat spread. J Therm Anal Calorim. 2007;88:351-4. doi:10.1007/s10973-0068070-8.

15. Lopez C, Lesieur P, Bourgaux C, Ollivon M. Thermal and structural behavior of anhydrous milk fat. 3. Influence of cooling rate. J Dairy Sci. 2005;88:511-26.

16. ten Grotenhuis E, van Aken GA, van Malssen KF, Schenk H. Polymorphism of milk fat studied by differential scanning calorimetry and real-time X-ray powder diffraction. J Am Oil Chem Soc. 1999;76:1031-9. 
17. Cebula DJ, Smith KW. Differential scanning calorimetry of confectionery fats. Part II. Effects of blends and minor components. J Am Oil Chem Soc. 1992;69:992-8.

18. Herrera ML, Segura JA, Rivarola GJ, Añón MC. Relationship between cooling rate and crystallization behavior of hydrogenated sunflower seed oil. J Am Oil Chem Soc. 1992;69:898-905.

19. Man YBC, Tan CP. Comparative differential scanning calorimetric analysis of vegetable oils. II. Effects of cooling rate variation. Phytochem Anal. 2002;13:142-51. doi:10.1002/pca.634.

20. Tan CP, Che Man YB. Differential scanning calorimetric analysis of palm oil, palm oil based products and coconut oil: effects of scanning rate variation. Food Chem. 2002;76:89-102.
21. Metin S, Hartel RW. Crystallization of fats and oils. In: Shahidi F, editor. Bailey's industrial oil and fat products. New York: Wiley Inc.; 2005. doi:10.1002/047167849X.bio021.

22. Herrera ML, Hartel RW. Effect of processing conditions on crystallization kinetics of a milk fat model system. J Am Oil Chem Soc. 2000;77:1177-88. doi:10.1007/s11746-000-0184-4.

23. Marangoni AG, Hartel RW. Visualization and structural analysis of fat crystal networks. Food Technol. 1998;52:46-51.

24. Von Ruegg M, Moor U, Blanc B. Eine verbesserte Methode zur Bestimmung des Schmelzdiagramms von Butterfett mit Hilfe registrierender Differential-Kalorimeter. Milchwissenschaft (Milk Sci Int.). 1983;38:601-5. 